JAMP: Jurnal Adminitrasi dan Manajemen Pendidikan

Volume 1 Nomor 4 Desember 2018, Hal : 467-471

Tersedia Online di http://journal2.um.ac.id/index.php/jamp/

ISSN 2615-8574 (online)

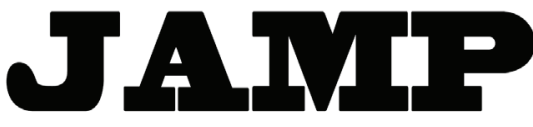

JURNAL ADMINISTRASI DAN MANAJEMEN PENDIDIKAN

\title{
PEMBERDAYAAN TENAGA ADMINISTRASI SEKOLAH MENENGAH PERTAMA KOTA BATU: STUDI DESKRIPTIF
}

\author{
Imam Gunawan \\ Teguh Triwiyanto \\ Desi Eri Kusumaningrum \\ Muhammad Romady \\ Mutya Alfarina \\ Riski Ariska Widiana \\ Universitas Negeri Malang, Jalan Semarang 5 Malang 65145 \\ Email: imam.gunawan.fip@um.ac.id
}

\begin{abstract}
Empowerment is the key to an organization's increasing productivity and organizational performance. Schools as educational organizations have human resources (HR) that handle administrative services, which are commonly called School Administration Staff (SAS). The question posed in this research is how high is the level of empowerment of the SAS Junior High School Batu City? To answer the research question, this study uses a quantitative research approach. The research sample was SAS Junior High School Batu City with a total of 25 people. To measure indicators of level of empowerment of SAS by using a questionnaire developed by Kusumaningrum et al., (2017a). The research data were analyzed using descriptive statistics, namely by calculating the mean, standard deviation, and category description of each item. The results of the data analysis concluded that the empowerment level of the SAS Junior High School Batu City with the highest frequency of 9 people (36\%) was in the good category and the average score was 70.2. Based on the description analysis category each item is known from 23 items, there are 7 items (30.43\%) included in the low category, and 16 items $(69.57 \%)$ are included in the high category.
\end{abstract}

Keywords: empowerment, school administration staff

\begin{abstract}
Abstrak: Pemberdayaan merupakan kunci organisasi meningkatkan produktivitas dan kinerja organisasi. Sekolah sebagai organisasi pendidikan memiliki sumber daya manusia (SDM) yang menangani layanan administrasi, yang lazim disebut Tenaga Administrasi Sekolah (TAS). Pertanyaan yang diajukan dalam penelitian ini adalah seberapa tinggi tingkat pemberdayaan TAS SMP Kota Batu? Untuk menjawab pertanyaan penelitian tersebut, penelitian ini menggunakan pendekatan penelitian kuantitatif. Sampel penelitian adalah TAS SMP Kota Batu dengan jumlah 25 orang. Untuk mengukur indikator tingkat pemberdayaan TAS dengan menggunakan angket yang dikembangkan oleh Kusumaningrum dkk., (2017a). Data penelitian dianalisis menggunakan statistik deskriptif, yaitu dengan menghitung rerata, deviasi standar, dan deskripsi kategori setiap item. Hasil analisis data menyimpulkan bahwa tingkat pemberdayaan TAS SMP Kota Batu dengan frekuensi tertinggi 9 orang (36\%) termasuk dalam kategori baik dan rerata skor sebesar 70,2. Berdasarkan analisis deskripsi

kategori setiap item diketahui dari 23 item terdapat 7 item (30,43\%) termasuk dalam kategori rendah, dan 16 item $(69,57 \%)$ termasuk dalam kategori tinggi.
\end{abstract}

Kata kunci: pemberdayaan, tenaga administrasi sekolah

Tenaga Administrasi Sekolah (TAS) merupakan ujung tombak pengelolaan administratif di sekolah. TAS memiliki peran yang penting dalam pengelolaan sekolah, seperti tata persurata sekolah, administrasi peserta didik, administrasi tenaga pendidik dan kependidikan, dan administrasi kurikulum. Pada umumnya pekerjaan kantor sekolah secara teknis dilakukan oleh TAS. Oleh sebab itu, menjadi hal 
penting memberdayakan kemampuan dan kompetensi TAS agar segenap tenaga dan waktunya dapat tercurahkan secara optimal untuk sekolah. Tujuan pemberdayaan adalah sebagai alat untuk membantu sumber daya manusia (SDM) yang dimiliki organisasi untuk mengomptimalkan kemampuannya (Hardina, dkk., 2007). Pemberdayaan merupakan wujud pengakuan kepada individu dari organisasi akan kemampuan yang dimiliki, sehingga ia selalu dalam kondisi siap sedia melakukan tugas yang diembannya (Kreitner dan Kinicki, 2010).

Sekolah dengan memberdayakan TAS bertujuan untuk mendukung proses penyelenggaraan pendidikan dan pencapaian tujuan sekolah (Surya, 2012). Oleh sebab itu, sekolah dalam memberdayakan TAS memerlukan kepemimpinan kepala sekolah yang baik (Sudharta, dkk., 2017) dan mampu membagi tugas dengan baik kepada seluruh SDM yang dimiliki sekolah. TAS memiliki peran melaksanakan kegiatan administrasi lembaga pendidikan dengan cara memberikan layanan prima dan optimal kepada semua pihak yang memerlukan layanan (Kusumaningrum, dkk., 2017b). Tujuan adanya pemberdayaan TAS adalah agar TAS yang dimiliki sekolah menjadi lebih berdaya dalam melaksanakan tugasnya. Hal ini mengingat bahwa layanan administrasi yang diselenggarakan oleh sekolah dilaksanakan oleh TAS (Gunawan dan Benty, 2017). Pertanyaan penelitian ini adalah seberapa tinggi tingkat pemberdayaan TAS SMP Kota Batu?

\section{METODE}

Penelitian ini menggunakan pendekatan penelitian kuantitatif. Penelitian dilaksanakan di SMP Kota Batu. Sampel penelitian adalah TAS dengan jumlah 25 orang. Instrumen penelitian adalah angket yang digunakan untuk mengukur tingkat pemberdayaan TAS dengan item berjumlah 23 item. Adapun angket penelitian ini adalah angket yang dikembangkan oleh Kusumaningrum, dkk., (2017a). Analisis data dengan menggunakan statistik deskriptif, yaitu dengan menghitung rerata, deviasi standar, dan deskripsi kategori setiap item (Gunawan, 2016b; Gunawan, 2013). Data penelitian disajikan dalam bentuk tabel distribusi frekuensi dengan mengacu pada formula stanfive (Wiyono dan Sunarni, 2009) guna menentukan kategori (Tabel 3).

\section{HASIL}

Data skor pemberdayaan TAS SMP Kota Batu ditampilkan pada Tabel 1. Berdasarkan pada Tabel 2, diketahui bahwa: skor minimum sebesar 57 ; skor maksimum sebesar 88 ; rerata sebesar 70,2; dan deviasi standar sebesar 7,88. Berdasarkan data pada Tabel 1, selanjutnya data pemberdayaan TAS SMP Kota Batu dideskripsikan dengan rumus formula stanfive (Tabel 2). Deskripsi frekuensi TAS SMP Kota Batu seperti ditampilkan pada Tabel 2.

Berdasarkan Tabel 2 diketahui bahwa dari 25 responden yang berada dalam interval skor: $>82,03$ sebanyak 1 orang (4\%) dengan kategori sangat baik; 74,14 s.d. 82,03 sebanyak 9 orang (36\%) dengan kategori baik; 66,26 s.d. 74,14 sebanyak 7 orang (28\%) dengan kategori cukup baik; 58,37 s.d. 66,26 sebanyak 6 orang (24\%) dengan kategori kurang baik; dan $<58,37$ sebanyak 2 orang (8\%) dengan kategori tidak baik. Berdasarkan pada Tabel 2 dapat disimpulkan bahwa tingkat pemberdayaan TAS SMP Kota Batu dengan frekuensi tertinggi 9 orang (36\%) termasuk dalam kategori baik. Hasil perbandingan rerata nilai semua item $(3,06)$ dengan rerata nilai setiap item ditampilkan pada Tabel 3 .

Berdasarkan analisis deskripsi kategori setiap item Tabel 3 dapat diketahui bahwa dari 23 item terdapat 7 item $(30,43 \%)$ termasuk dalam kategori rendah, karena rata-rata nilai setiap item tersebut $\leq$ rata-rata nilai semua item. Item yang termasuk dalam kategori rendah yaitu item nomor: 6, 9, 10, 11, 14, 19, dan 22. Hal ini berarti bahwa pelaksanaan jabaran indikator pemberdayaan TAS yang terdapat dalam nomor-nomor item tersebut harus ditingkatkan. Sedangkan 16 item $(69,57 \%)$ termasuk dalam kategori tinggi, karena rata-rata nilai setiap item tersebut $>$ rata-rata nilai semua item. Item yang termasuk dalam kategori tinggi yaitu item nomor: $1,2,3,4,5,7,8,12,13,15,16,17,18,20,21$, dan 23. Hal ini berarti bahwa pelaksanaan jabaran indikator pemberdayaan TAS yang terdapat dalam nomor-nomor item tersebut harus dipertahankan. 
Tabel 1 Data Skor Pemberdayaan TAS SMP Kota Batu

\begin{tabular}{cccc}
\hline Item & Skor & Item & Skor \\
\hline 1 & 88 & 15 & 76 \\
2 & 78 & 17 & 73 \\
3 & 63 & 18 & 63 \\
4 & 76 & 19 & 57 \\
5 & 74 & 20 & 60 \\
6 & 76 & 21 & 76 \\
7 & 69 & 22 & 75 \\
8 & 58 & 23 & 60 \\
9 & 69 & 24 & 60 \\
10 & 78 & 25 & 69 \\
11 & 75 & & \\
12 & 69 & Min & 57 \\
13 & 69 & Max & 88 \\
14 & 65 & X & 70,2 \\
16 & 79 & DS & 7,88 \\
\hline
\end{tabular}

Tabel 2 Distribusi Frekuensi Pemberdayaan TAS Kota Batu

\begin{tabular}{|c|c|c|c|c|c|}
\hline No & Formula & Interval & $\mathbf{F}$ & $\%$ & Kategori \\
\hline 1 & $(\overline{\mathrm{X}}+1.5 \mathrm{SD})<\mathrm{X}$ & $>82,03$ & 1 & 4 & Sangat baik \\
\hline 2 & $(\overline{\mathrm{X}}+0.5 \mathrm{SD})<\mathrm{X}<(\overline{\mathrm{X}}+1.5 \mathrm{SD})$ & 74,14 s.d. 82,03 & 9 & 36 & Baik \\
\hline 3 & $(\overline{\mathrm{X}}-0.5 \mathrm{SD})<\mathrm{X}<(\overline{\mathrm{X}}+0.5 \mathrm{SD})$ & 66,26 s.d. 74,14 & 7 & 28 & Cukup baik \\
\hline 4 & $(\bar{X}-1.5 \mathrm{SD})<\mathrm{X}<(\overline{\mathrm{X}}-0.5 \mathrm{SD})$ & 58,37 s.d. 66,26 & 6 & 24 & Kurang baik \\
\hline 5 & $\mathrm{X}<(\overline{\mathrm{X}}-1,5 \mathrm{SD})$ & $<58,37$ & 2 & 8 & Tidak baik \\
\hline & Jumlah & & 25 & 100 & \\
\hline
\end{tabular}

Tabel 3 Deskripsi Kategori Setiap Item (Perbandingan Rerata Nilai Semua Item dengan Setiap Item)

\begin{tabular}{|c|c|c|c|c|c|c|c|c|c|}
\hline Item & $\Sigma$ & $\mathrm{n}$ & $\bar{X}$ & Ket & Item & $\sum$ & $\mathrm{n}$ & $\overline{\mathrm{X}}$ & Ket \\
\hline 1 & 86 & 25 & 3,44 & $\mathrm{~T}$ & 13 & 80 & 25 & 3,20 & $\mathrm{~T}$ \\
\hline 2 & 84 & 25 & 3,36 & $\mathrm{~T}$ & 14 & 57 & 25 & 2,28 & $\mathrm{R}$ \\
\hline 3 & 84 & 25 & 3,36 & $\mathrm{~T}$ & 15 & 83 & 25 & 3,32 & $\mathrm{~T}$ \\
\hline 4 & 83 & 25 & 3,32 & $\mathrm{~T}$ & 16 & 80 & 25 & 3,33 & $\mathrm{~T}$ \\
\hline 5 & 86 & 25 & 3,44 & $\mathrm{~T}$ & 17 & 82 & 25 & 3,28 & $\mathrm{~T}$ \\
\hline 6 & 69 & 25 & 2,88 & $\mathrm{R}$ & 18 & 83 & 25 & 3,32 & $\mathrm{~T}$ \\
\hline 7 & 82 & 25 & 3,28 & $\mathrm{~T}$ & 19 & 69 & 25 & 2,76 & $\mathrm{R}$ \\
\hline 8 & 87 & 25 & 3,48 & $\mathrm{~T}$ & 20 & 85 & 25 & 3,40 & $\mathrm{~T}$ \\
\hline 9 & 51 & 25 & 2,04 & $\mathrm{R}$ & 21 & 82 & 25 & 3,28 & $\mathrm{~T}$ \\
\hline 10 & 60 & 25 & 2,40 & $\mathrm{R}$ & 22 & 52 & 25 & 2,08 & $\mathrm{R}$ \\
\hline 11 & 64 & 25 & 2,56 & $\mathrm{R}$ & 23 & 78 & 25 & 3,12 & $\mathrm{~T}$ \\
\hline 12 & 88 & 25 & 3,52 & $\mathrm{~T}$ & Rerata & 76,3 & - & 3,06 & - \\
\hline
\end{tabular}




\section{PEMBAHASAN}

Hasil penelitian ini menyimpulkan bahwa tingkat pemberdayaan TAS SMP Kota Batu termasuk dalam kategori baik. Simpulan penelitian ini mengindikasikan bahwa pemberdayaan TAS di SMP Kota Batu dilaksanakan dengan baik. Pemberdayaan staf membutuhkan kemampuan pemimpin untuk memperlakukan staf sebagai mitra dan bukan sebagai bawahan semata (Sudayat, 2014; Gunawan, dkk., 2018). Pemberdayaan staf berkaitan dengan kepemimpinan dan kreativitas yang dimiliki oleh staf (Özarall, 2015; Gunawan, 2017b). Oleh sebab itu, sebelum memberdayakan TAS, kepala sekolah itu sendiri harus mampu memberdayakan dirinya sendiri untuk kemajuan sekolah (Kusumaningrum, dkk., 2018; Sultoni, dkk., 2018a; Pertiwi, dkk., 2018).

Profesionalisme TAS akan terwujud dengan adanya dukungan dari kepala sekolah, yaitu dengan memprogram berbagai kegiatan yang dapat menunjang pemberdayaan TAS (Wibowo, 2015; Sultoni, dkk., 2018b). Program yang dapat meningkatkan pemberdayaan TAS adalah dengan memberikan kesempatan kepada TAS untuk mengikuti kegiatan pelatihan komputer, pelatihan pengelolaan kantor, dan pelatihan public speaking. Kunci layanan administrasi sekolah dapat terselenggara dengan baik adalah adanya pemberdayaan TAS yang baik. Pemberdayaan TAS dapat dilaksanakan secara sistematis dan kontinu manakala sekolah juga memperhatikan upaya memberikan dampak positif pemberdayaan TAS bagi peningkatan kemampuan dan kesejahteraan TAS (Mahri, 2004; Kusmintardjo dan Gunawan, 2017; Benty dan Gunawan, 2015).

Hal tersebut selaras dengan tuntutan beban kerja TAS saat ini, misalnya tugas administrasi Kurikulum 2013, pengelolaan data pokok pendidikan, dan administrasi kesiswaan (Gunawan, 2017a; Gunawan, 2016a). Oleh sebab itu, pemberdayaan harus linier dengan upaya peningkatan kesejahteraan staf (Gunawan dan Benty, 2007; Mursidik, dkk., 2013). Selain itu, hal yang tidak kalah krusial adalah upaya melakukan peningkatan kompetensi TAS dalam mengoperasikan sarana yang berbasis teknologi informasi. Saat ini pekerjaan TAS tidak terlepas dari penggunaan sarana teknologi informasi. Keterampilan memanfaatkan sarana teknologi informasi dapat memudahkan TAS melaksanakan tugas administrasi sekolah.

\section{KESIMPULAN}

Kesimpulan penelitian ini adalah tingkat pemberdayaan TAS SMP Kota Batu dengan frekuensi tertinggi 9 orang $(36 \%)$ termasuk dalam kategori baik dan rerata skor sebesar 70,2. Temuan ini menguatkan teori tentang urgensi dari pemberdayaan staf untuk meningkatkan produktivitas staf. Kepala sekolah perlu membuat program pemberdayaan yang komprehensif dengan memperhatikan segenap kompetensi yang dimiliki oleh staf.

\section{DAFTAR RUJUKAN}

Benty, D. D. N., dan Gunawan, I. 2015. Manajemen Hubungan Sekolah dan Masyarakat. Malang: Universitas Negeri Malang, UM Press.

Gunawan, I. 2013. Statistika untuk Kependidikan Sekolah Dasar. Yogyakarta: Penerbit Ombak Yogyakarta.

Gunawan, I. 2016a. Model of Educational Leadership in the Implementation of Curriculum 2013. Proceedings The $4^{\text {th }}$ International Conference Language, Society, and Culture in Asian Contexts (LSCAC 2016) on Cultivating and Casting Asian Diversities: Empowering the Asians, Universitas Negeri Malang, Malang, 24 s.d. 25 Mei, hlm. 1109-1118.

Gunawan, I. 2016b. Pengantar Statistika Inferensial. Jakarta: Rajawali Pers.

Gunawan, I. 2017a. Indonesian Curriculum 2013: Instructional Management, Obstacles Faced by Teachers in Implementation and the Way Forward. Proceeding $3^{\text {rd }}$ International Conference on Education and Training $\left(3^{\text {rd }}\right.$ ICET) 2017, Theme: Global and Local Based Education and Training, Faculty of Education State University of Malang, Published by Atlantis Press, September 30 - Oktober 1, hlm. 56-63.

Gunawan, I. 2017b. Landasan Dasar Pendidikan. Malang: Universitas Negeri Malang, UM Press.

Gunawan, I., dan Benty, D. D. N. 2007. Musyawarah Guru Mata Pelajaran dan Kemampuan Mengelola Kelas untuk Meningkatkan Motivasi Belajar Siswa. Manajemen Pendidikan, 20(1), 21-31. 
Gunawan, I., dan Benty, D. D. N. 2017. Manajemen Pendidikan: Suatu Pengantar Praktik. Bandung: Alfabeta.

Gunawan, I., Triwiyanto, T., dan Kusumaningrum, D. E. 2018. Pendampingan Penulisan Artikel Ilmiah bagi Para Guru Sekolah Menengah Pertama. Abdimas Pedagogi: Jurnal Ilmiah Pengabdian kepada Masyarakat, 1(2), $128-135$.

Hardina, D., Middleton, J., Montana, S., dan Simpson, R. A. 2007. An Empowering Approach to Managing Social Service Organizations. New York: Springer Publishing Company.

Kreither, R., dan Kinicki, A. 2010. Organizational Behavior. New York: McGraw-Hill Companies, Inc.

Kusmintardjo, dan Gunawan, I. 2017. Manajemen Layanan Khusus. Malang: Universitas Negeri Malang, UM Press.

Kusumaningrum, D. E., Sumarsono, R. B., dan Gunawan, I. 2017a. Pengembangan Model Pemberdayaan Sumber Daya Manusia Sekolah Menengah Pertama Berbasis Pesantren dengan Pendekatan Soft System Methodology. Laporan penelitian tidak diterbitkan (tahun pertama). Malang: LP2M Universitas Negeri Malang.

Kusumaningrum, D. E., Sumarsono, R. B., dan Gunawan, I. 2017b. Pemberdayaan Tenaga Administrasi Sekolah Menengah Pertama Berbasis Pesantren. Prosiding Seminar Nasional Pendidikan Sinergitas Keluarga, Sekolah, dan Masyarakat dalam Penguatan Pendidikan Karakter, Fakultas Ilmu Pendidikan Universitas Negeri Malang, Malang, 16 November, hlm. 127-138.

Kusumaningrum, D. E., Sumarsono, R. B., dan Gunawan, I. 2018. Empowering the Principal of Boarding HouseBased Junior High School in East Java Province Indonesia. Proceeding $3^{\text {rd }}$ International Conference on Education Management and Administration (CoEMA 2018), Theme: The Challenges of Education and Technology in Global and Local Era, Faculty of Education State University of Malang, Published by Atlantis Press, 6-7 Oktober, hlm. 147-151.

Mahri, A. J. W. 2004. Implementasi Pengintegrasian Pola Pemberdayaan Guru Sukwan, (Online), (http://jurnal. upi.edu/file/A._Jajang_M_.pdf), diakses 2 Mei 2017.

Mursidik, E. M., Tryanasari, D., dan Gunawan, I. 2013. Pengembangan Buku Pedoman Microteaching Berbasis Lesson Study Prodi PGSD FIP IKIP PGRI MADIUN. Jurnal Pendidikan, 19(1), 1-26.

Özarall, N. 2015. Linking Empowering Leader to Creativity: The Moderating Role of Psychological (Felt) Empowerment, (Online), International Conference on Leadership, Technology and Innovation Management, Procedia - Social and Behavioral Sciences, hlm. 447-454, (http://www.sciencedirect.com), diakses 13 Oktober 2015.

Pertiwi, A. K., Cahyani, S. S. A., Diana, R. C., dan Gunawan, I. 2018. Analisis Interaksi Simbolik Kyai dan Santri dalam Perspektif Kepemimpinan Berbasis Nilai dan Etika. JMSP: Jurnal Manajemen dan Supervisi Pendidikan, 2(3), 185-191.

Sudayat, A. T., Ulfatin, N., dan Sobri, A. Y. 2014. Pemberdayaan dan Pengembangan Sumber Daya Manusia pada Sekolah Inklusi. Ilmu Pendidikan, 41(2), 109-115.

Surya, P. 2012. Peran Penting Tenaga Administrasi Sekolah dalam Penguatan Budaya Sekolah untuk Implementasi Pendidikan Karakter. Makalah disajikan dalam Seminar Nasional dan Temu Alumni Dies Natalis ke-48 UNY Tahun 2012, Tema Implementasi Pendidikan Karakter dalam Membangun Bangsa, Dewan Pengurus Pusat Ikatan Alumni Universitas Negeri Yogyakarta, Yogyakarta, 5 Mei.

Sudharta, V. A, Mujiati, M., Rosidah, A., dan Gunawan, I. 2017. Gaya Kepemimpinan Kepala Sekolah dalam Perspektif Psikologi. Manajemen dan Supervisi Pendidikan, 2(2), 109-123.

Sultoni, Gunawan, I., dan Rosalinda, T. N. 2018a. Pengaruh Pembentukan Tim dan Kepemimpinan Spiritual terhadap Motivasi Diri Mahasiswa. JMSP: Jurnal Manajemen dan Supervisi Pendidikan, 2(3), 210-216.

Sultoni, Gunawan, I., dan Sari, D. N. 2018b. Pengaruh Etika Profesional terhadap Pembentukan Karakter Mahasiswa. JAMP: Jurnal Adminitrasi dan Manajemen Pendidikan, 1(3), 279-283.

Wibowo, C. H. 2015. Problematika Profesi Guru dan Solusinya bagi Peningkatan Kualitas Pendidikan di MTs Negeri Nguntoronadi Kabupaten Wonogiri. Thesis. Surakarta: Institut Agama Islam Negeri Surakarta.

Wiyono, B. B., dan Sunarni. 2009. Evaluasi Program Pendidikan dan Pembelajaran. Malang: Fakultas Ilmu Pendidikan Universitas Negeri Malang. 